\title{
TERBENTUKNYA IDENTITAS FANS SEPAK BOLA SEBAGAI BUDAYA MASSA DALAM INDUSTRI MEDIA
}

\author{
Iswandi Syahputra \\ Dosen Ilmu Komunikasi Fakultas Ilmu Sosial dan Humaniora \\ UIN Sunan Kalijaga Yogyakarta \\ ditra73@yahoo.com
}

\begin{abstract}
Nowadays football is not merely sport. It has become industry, even popular culture. This happen because on the same time mass media grows into mass culture industry. The union of football and mass media as industry has melted few social and culture boundaries. Socially-through mass media-football had joined many social background into football fans identity, and it even connect all over the world. Football had transformed into popular culture that always moves in instability that drain its fans's emotion. The football fans emotion in turn polarised into fans club which was created based on imaginary bound. Fans is the most visible part from text society and pop culture practice that could become fanatic. This fans fanatism phenomena could happen because the fans are pasif and patologic victim of mass media. This phenomena also mark the indication of transition from agricultural society into industrial and urban society.
\end{abstract}

Keywords: Football, Fans, Identity

\begin{abstract}
Abstrak
Saat ini sepakbola bukan hanya sekadar olahraga. Sepakbola telah menjadi sebuah industri dan juga budaya populer. Hal ini terjadi bersamaan dengan berkembangnya media massa menjadi industri budaya massa. Persatuan sepakbola dan media massa sebagai sebuah industri telah menghilangkan batasan antara sosial budaya. Secara sosial, melalui media massa sepakbola telah menjdai latar belakang sosial bagi identitas para penggemar sepakbola, dan sepakbola menghubungkan semua hal di seluruh dunia. Sepakbola telah bertransformasi menjadi budaya bahkan populer yang selalu bergerak dalam ketidakstabilan yang memicu emosi para penggemar. Emosi para penggemar sepakbola terpolarisasi ke dalam sebuah grup para penggemar yang terbentuk berdasarkan ikatan abstrak. Penggemar merupakan bagian penting dari konteks masyarakat dan budaya populer yang dapat menjadi fanatik. Fenomena fanatisme penggemar ini dapat terjadi karena penggemar adalah korban pasif dan patologis dari media massa. Fenomena ini juga menandakan transisi dari masyarakat agraris menuju masyarkat industri dan masyarakat modern.
\end{abstract}

Kata Kunci: Sepakbola, Penggemar, Identitas 


\section{PENDAHULUAN}

Di berbagai kota besar, di Indonesia sejumlah orang malam dini hari, keluar dari rumah untuk berkumpul bersama guna menghadiri upacara/ritual nonton bareng yang biasa disebut dengannobar. Karena selisih perbedaan waktu sekitar 7 jam, setiap pertandingan sepak bola yang digelar siang atau sore hari di Eropa selalu ditayangkan malam atau dini hari waktu Indonesia. Mereka meninggalkan rumah menuju suatu tempat upacara/ritual diselenggarakannya nobar, biasanya di cafe atau warung terbuka yang luas. Jika tempatnya tidak cukup, beberapa cafe menutup sebagian jalan untuk menampung membludaknya jamaat sepak bola tersebut. Mereka hadir dengan membawa atau menggunakan berbagai atribut seperti jersey, syal, topi atau bendera klub sepak bola yang mereka dukung. Karena diselenggarakan di tempat komersial, upacara/ritual nonbar tidak gratis, setiap yang hadir dipungut biaya. Hal itu mereka lakukan bukan saja untuk menonton klub sepak bola kesayangan mereka, tapi demi sebuah identitas yang mereka pilih. Di dalamnya ada pengorbanan, kegembiraan bersama atau solidaritas, bahkan gaya hidup dan gengsi.

Saat ini memang sepak bola berkembang cukup pesat, bukan saja sekedar olah raga yang menghibur tetapi menjadi sebuah industri olah raga, hiburan, wisata, gaya hidupyang terintegrasi dan termediasi dalam kultur media yang dominan. Sepak bola menjadi olah raga paling populer di dunia. Coakley (2001) menilai popularitas sepak bola sebagai olah raga di dunia karena populer, memiliki pangsa pasar yang jelas dan besar, adanya pertumbuhan kelas menengah yang memiliki waktu, uang, transportasi dan koneksi media serta dekat dengan masyarakat yang mengikuti gaya hidup yang mengutamakan konsumsi dan simbol status materi. Peran media massa, terutama televisi, memiliki kemampuan mengintegrasikan itu semua menjadi sebuah identitas sosial yang bersifat imajiner namun mampu menembus ruang dan waktu.
Hal tersebut memungkinkan terjadi karena pada saat bersamaan media massa tumbuh sebagai industri budaya massa. Pertemuan dua industri raksasa (sepak bola dan media massa) telah melelehkan beberapa sekat sosial, budaya bahkan religiusitas yang selama ini berlangsung dengan ketat. Secara sosial-melalui media massa-sepak bola mampu mempertemukan berbagai latar belakang sosial dalam suatu identitas fans sepak bola, bahkan hingga menjalin antar benua. Demikian juga secara budaya, industri sepak bola yang termediasi melalui media massa tersebut mampu menciptakan budaya baru. Suatu budaya massa yang instan dan sesaat namun berisfat masif dan fanatik. Fanatisme ini bahkan bisa melampaui keyakinan religiusitas.

Sepakbolatelahbertransformasimenjadi kultur populer yang selalu bergerak dalam suatu ketidakstabilan yang menguras emosi pemujanya. Emosi penggemar sepak bola tersebut padagilirannya terpolarisasi menjadi fans club yang terbentuk berdasarkan suatu ikatan yang bersifat imajiner. Dalam sebuah kunjungan singkat ke sejumlah stadion sepak bola di Eropa, saya sangat merasakan kekuatan ikatan imajiner tersebut. Saat memasuki kandang klub sepak bola raksasa Manchester United (MU) di stadion Old Trafford, Manchester, para Mancunian dari berbagai negara langsung merasa terikat dalam suatu balutan emosi sesama fans MU. Perasaan bangga sebagai fans MU demikian mewarnai kunjungan tersebut. Kelak hal serupa terjadi kembali pada sejumlah stadion lain yang saya kunjungi.

Kehadiran fisik ke stadion Old Trafford sudah cukup sebagai tanda kuatnya ikatan yang bersifat emosional tersebut. Emosi tersebut tentu tidak muncul tiba-tiba, mendadak bangga menjadi fans MU di Old Tarfford. Sebelumnya telah terjadi proses penciptaan emosi melalui sebuah konstruksi simbol atau ritual bersama seperti nonton bareng berbagai laga MU di negara masingmasing. Anderson (1999) menyebut ini sebagai komunitas imajiner, yaitu sebuah konstruksi yang diciptakan lewat berbagai simbol dan ritual yang dikokohkan melalui 
berbagai sarana komunikasi seperti siaran langsung pertandingan sepak bola melalui televisi. Berbagai produksi informasi tentang MU, misalnya, telah menetapkan berbagai standar yang menyediakan berbagai kondisi terbentuknya suatu kesadaran untuk mencintai MU.

\section{Mengidentifikasi Identitas}

Identitas identik dengan konsep diri dan secara sosial dapat berfungsi sebagai diferensiasi dari orang lain. Suatu identitas menjadi melekat dalam diri seseorang melalui proses yang sangat panjang. Berbagai pertimbangan digunakan untuk mengidentifikasi diri dengan suatu identitas. Karena itu suatu identitas selalu dapat dirujuk pada suatu yang membentuknya, seperti adanya keberadaan reference group atau significant others bagi seseorang tersebut. Identitas menjadi suatu proses sadar diri berupa observasi terhadap diri sendiri untuk menemukan konsep diri sebagai suatu yang utuh. Secara sederhana Charon (2007: 86) memberi pengertian identitas sebagai the name we call ourselves, and usually it is the name we announce to others that we are as we act in situations.

Dalam prosesnya, identitas diri terjadi dengan melibatkan hal yang kompleks, dinamis dan selalu dapat berubah sepanjang hidup. Dalam berbagai keadaan yang terus berubah, identitas menjadi penting sebagai modus eksistensi. Marcia (1993) menjelaskan, identitas diri terbentuk dari dua komponen penting yaitu eksplorasi dan komitmen. Eksplorasi dimaknai sebagai proses a period ofstruggling or active questioning in arriving at decision about goals, values, and beliefs. Pada priode ini, segala macam hal tentang tujuan, nilai dan kepercayaan secara dinamis dipertimbangkan untuk ditetapkan sebagai pegangan diri. Sedangkan komitmen adalah a making relatively firm choice about identity element and enganging in significant activity directed toward implementation of that choice. Suatu kondisi dimana pilihan telah ditetapkan setelah eksplorasi diri dilakukan. Pilihan tersebut dikukuhkan dalam diri sebagai komitmen terhadap diri sendiri. Komitmen tersebut dapat diukur jika elemen identitas berfungsi mengarahkan tindakannya dan tidak membuat perubahan yang berarti terhadap elemen identitas tersebut.

Kendati identitas merupakan persoalan identifikasi diri, namun suatu identitas tidak melekat menjadi bawaan sejak lahir. Identitas terbentuk dalam suatu institusi. Samovar (2010) menjelaskan, budaya merupakan arena yang dapat membantu individu dalam masyarakat untuk menemukan identitas dirinya. Pada tahap awal proses mencari identitas diri ini, reference group atau significant others sangat menentukan komitmen seseorang pada identitas yang dipilihnya. Reference group atau significant others tersebut dapat berupa keluarga, teman atau kelompok etnis bahkan media massa. Karena itu,Hogg (2001: 125) membagi dua tipe identitas, identitas diri (personal identity) dan identitas sosial (social identity). Kedua identitas itu nantinya membentuk self image.

Selain faktor budaya dan reference group atau significant others, media massa termasuk lingkungan yang turut mempengaruhi seseorang mengidentifikasi identitas dirinya secara sosial. Terutama media televisi yang memiliki kekuatan ganda sebagai kebudayaan material sekaligus mesin pencipta kebudayaan populer. Dalam buku Television Culture, Fiske (1987)mendefenisikan televisi sebagai pembatas/provokator makna dan kesenangan, dan budaya sebagai generasi dan sirkulasi berbagai makna dan kesenangan dalam masyarakat. Televisi sebagai budaya adalah bagian penting dari dinamika sosial dimana struktur sosial menjaga dirinya sendiri dalam proses produksi dan reproduksi yang konstan ; makna, kesenangan popular dan sirkulasinya menjadi bagian dan paket dari struktur sosial.

Melalui televisi, berbagai ragam praktek simbolik diproduksi. Televisi menjadi medium untuk pertukaran simbolsimbol kebudayaan. Tomlinson (1999: 18) menjelaskan proses ini sebagai budaya yang dibangun melalui makna dan praktek 
representasi simbolik. Selain sebagai produk kebudayaan material, di saat bersamaan televisi juga berperan sebagai agen yang memproduksi kebudayaan turunannya, seperti style, gengsi, bahasa dan konsumsi. Terdapat semacam lapisan "budaya dalam budaya" atau "budaya memproduksi budaya", karena televisi memiliki kekuatan panetrasi pembentuk budaya massa. Pemilihan dan penggunaa simbol-simbol kebudayaan oleh televisi memasuki level pemberian "defenisi sosial" dari sebuah budaya. Defenisi-defenisi sosialdan kebudayaan produkindustritelevisi yang sesungguhnya artifisial tersebutlah yang memunculkan identitas sosial.

Identitas disini berarti 'pemahaman' tentang kelompok yang direpresentasikansebuah pemahaman ihwal siapa mereka, bagaimana mereka dinilai, bagaimana mereka dilihat oleh orang lain. Pemahaman tersebut bisa secara umum dimiliki oleh oleh anggota kelompok itu dan oleh orang lain diluar kelompok tersebut. Kendati demikian, pemahaman yang menyeluruh tentang identitas kelompok oleh anggotanya besar kemungkinan berbeda dengan pandangan yang dikonstruksikan oleh mereka yang berada di luar kelompok. Dalam pengertian ini, identitas merupakan sebuah konsep yang sulit dipegang, bermakna berbeda untuk orang yang berbeda dalam situasi yang berbeda, terutama mereka yang tersangkut di dalam dan di luar kelompok, namun juga memuat makna bersama.

Identitas adalah sesuatu yang ada dalam kesadaran, diartikulasikan dalam komunikasi dan juga dihidupkan oleh sebuah konteks budaya. Televisi dapat membantu mendefenisikan dalam memberikan pemahaman terhadap identitas tersebut (Barton, 2000: 288). Identitas dalam budaya massa adalah suatu yang diproduksi, bukan esensi yang tetap dan menetap. Dengan begitu, identitasselalu berproses, selalu membentuk, di dalam-bukan di luar-representasi. Ini juga berarti otoritas dan keaslian identitas dalam konsep "identitas kultural" misalnya, berada dalam masalah. Identitas hanya bisa ditandai dalam perbedaan sebagai suatu bentuk representasi dalam sistem simbolik maupun sosial, untuk melihat diri sendiri tidak seperti yang lain.

\section{HASIL DAN PEMBAHASAN}

\section{Media dan Pembentukan Identitas Fans Sepak Bola}

Jhonson (2006) memberi beberapa asumsi konstruksi identitas dalam media. Pertama identitas adalah self defined (ditentukan oleh diri sendiri), bukan diberikan oleh seseorang atau oleh orang lain, organisasi atau masyarakat termasuk bukan ditentukan oleh televisi. Konstruksi identitas tersebut dapat meliputi melakukan aksi perlawanan terhadap stereotype negatif yang diberikan orang lain pada kelompok yang memiliki identitas (Collier, 1998). Beberapa orang akan menambahkan bahwa identitas budaya bukan hanya self identification, tapi recognition (pengenalan) dan penerimaan self identification tersebut oleh anggota lain dari kelompok tersebut (Tanno dan Gonzales, 1998). Kedua, identitas bergerak dari lokal ke transnasional. Ketiga, identitas adalah situasional (Rodriguez, 200o, Subervi Velez, 1994). Seperti Rodriguez (2000), Jhonson menekankan bahwa individual memiliki sebuah inti self identity, namun identitas yang lebih luas (seperti etnik, nasionalisme dan agama) seseorang bergeser bergantung pada situasi dan hubungan dengan orang lain dalam konteks tertentu (dalam Valdivia, 2006: 273-274).

Dari asumsi konstruksi identitas dalam media dari Jhonson tersebut dapat disimpulkan bahwa fungsi media termasuk cerminan kompleks dari identitas budaya. Identitas meliputi identitas seseorang dalam masyarakat yang lebih luas (terutama saat berhubungan dengan etnisitas, kelas, agama dan konsumsi orientasi). Anggota kelompok etnik/paham agama dapat menunjukkan berbagai kombinasi dari tingkat-tingkat ini bergantung pada situasi atau konteks kelompok. Hibriditas menjelaskan zona dimana berbagai aspek dari identitasidentitas ini bertemu; menciptakan sebuah tingkat ketegangan internal, tetapi juga memungkinkan kombinasi menarik yang 
dapat menguntungkan individu. Penjelasan berikut menekankan bagaimana bentukbentuk identitas dan ketegangan ini dapat diilustrasikan dalam sebuah model media yang mengkonstruksi identitas. Model ini digambarkan dalam figure sebagai berikut (Valdivia, 2006: 277-278) :

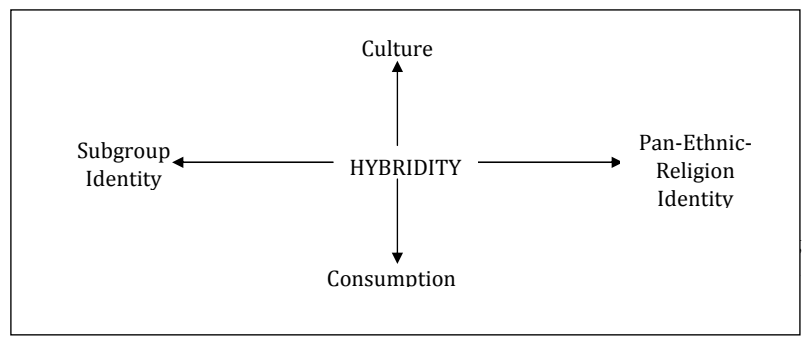

Pendapat lain tentang identitas dan televisi muncul dari Barker (2005) yang menyatakan, mengkonsumsi televisi dapat membentuk bentuk identitas kultural. Televisi menjadi sumber pembentuk identitas kultural dan pemirsa menggunakan identitas dan kompetensi kultural mereka untuk mendekode program dengan cara yang khas masing-masing. Seiring dengan mengglobalnya televisi, perannya dalam pembentukan identitas etnis dan nasional menjadi semakin penting. Yang paling penting adalah, dapat disimpulkan bahwa pemirsa menggunakan identitas nasional, etnis, budaya (dan agama) mereka sendiri sebagai posisi untuk membaca/medekode program televisi. Televisi tidak begitu saja dikonsumsi pemersinya yang bisa dengan mudah merusak identitas kultural yang indegenous Barker (2005: 361).

Oleh karena itu, nilai penting televisi bukan hanya pada apa makna tekstual dan penafsirannya tapi juga pada tempatnya dalam ritme dan rutinitas kehidupan domestik sehari-hari.Menontontelevisiadalah kegiatanyang biasa dilakukan di ruang domestik tertentu, seperti ruang keluarga. Ruang menonton dan aktivitas dengan begitu turut menentukan identitas. Ruang menurut Massey (1994) (dalam Barker, 2005:363) bukanlah suatu yang hampa melainkan diproduksi secara kultural oleh hubungan sosial. Artinya, ada ruang rumah, ruang bangsa, ruang kelas, kamar depan dikonstruksi di dalam dan melalui hubungan sosial dan agar tempat berubah menjadi ruang, ia harus dipenuhi dengan komitmen emosional. Perbedaan ruang (space)dantempat(place)menurutSilverstone (1994) dicirikan oleh perasaan. Ruang adalah tempat yang dipenuhi pengalaman, ingatan dan hasrat manusia yang bertindak sebagai patokan identitas individual dan kolektif yang penting.

Walau terbagi dalam dua tipe, identitas personal dan identitas sosial/kultural, namun identitas itu saling mempengaruhi karena menjadi bagian dari satu kesatuan diri. Identitas personal dipengaruhi oleh identitas sosial, sebaliknya identitas sosial juga dipengaruhi oleh identitas personal. Saat seseorang menjadi bagian dari suatu identitas kelompok pada saat itu pula identitas sosialnya mulai terbentuk. Dengan demikian suatu identitas sosial merupakan bagian dari kumpulan konsep diri individu yang bersumber dari observasi dan komitmen mereka terhadap nilai yang dipegang oleh suatu kelompok. Nilai yang dipegang secara kuat tersebut dapat menstimulasi fanatis kelompok. Fanatisme ini sangat mempengaruhi perkembangan identitas seseorang.

Dalam olah raga, sepak bola misalnya, sesama individu yang memiliki ketertarikan pada suatu nilai yang terkandung dalam suatu klub sepak bola dapat membuka jalan terbentuknya identitas kelompok, yang biasa disebut sebagai fans club. Nilai-nilai ketertarikanindividu,yangtengahmelakukan observasi terhadap dirinya, terhadap sepak bola biasanya terkait dengan harga diri, pelarian dari kehidupan sehari-hari, atau sekedar sebagai hiburan. Pada tahap awal saat observasi diri sebelum memutuskan pilihan menjadifans klub sepak bola, seorang individu memiliki ketertarikan awal terhadap sepak bola atau yang terkait dengannya. Tidak melulu hanya terkait pada permainan sepak bola, dapat saja tertarik terlebih dahulu dengan jersey yang dikenankan atau tertarik pada prilaku supporters. Oleh sebab itu, Giulianotti sebagaimana dikutip Munro (2000: 5) membagi empat tipe spectators (penonton), yaitu supporters (pendukung), followers (pengikut), fans (penggemar), dan flaneurs. 
Berbeda dengan Giulianotti, pendapat lain dikemukakan Jacobson (2003: 6) yang berpandangan bahwa fans berbeda denga spectator yang hanya menonton, sedikit mengamati dan mudah melupakannya. Fans memiliki intensitas yang stabil mengikuti perjalanan dan perkembangan klub sepak bola yang disukainya. Fanship dapat didefinisikan sebagai afiliasi di mana banyak makna emosional dan nilai yang berasal dari keanggotaan kelompok. Fans merupakan penikmat sepak bola yang turut mencurahkan perhatiannya untuk berfikir, berbicara dan berorientasi pada klub sepak bola yang digemarinya. Ada kegairahan dan spirit yang berbeda antara spectator dan fans. Seorang penonton sepak bola belum tentu fans dari klub yang ditontonnya. Demikian juga sebaliknya, seorang fans klub sepak bola belum tentu menonton seluruh pertandingan klub yang digemarinya. Sebab keterikatan seorang fans bukan pada aktivitas menontonnya tetapi pada pengetahuan terhadap klub yang digemarinya tersebut.

Namun demikian, untuk kepentingan menyokong sepak bola yang kini telah memasukimedanindustriyangpenuhdengan berbagai persaingan ketat, manajemen klub memiliki mekanisme untuk mendata anggota fans-nya. Cara yang paling mudah dan lazim dilakukan biasanya dengan membuat fans $c l u b$ di setiap negara yang terdaftar resmi di markas negara asal klub sepak bola tersebut. Identitas fans yang seharusnya diperoleh melalui proses identifikasi diri menjadi tereduksi secara administratif melalui pendaftaran dan kepemilikan kartu anggota. Kartu anggota fans club itu memiliki masa berlaku terbatas. Karena itu, pada era global seperti ini, dimana jumlah fans sepak bola menyebar hampir di seluruh pelosok dunia, sangat sulit sekali memastikan jumlah fans dari sebuah klub sepak bola.

Kendati sulit memastikan jumlah fans suatu klub sepak bola di seluruh dunia, namun fans tetap merupakan aset bagi klub sepak bola. Aset ini tentu dibutuhkan untuk memperkuat branding dan positioning sebuah klub sepak bola untuk mempertahankan pengaruhnya. Kepastian jumlah fans menjadi bertambah penting dan strategis sebagai marketing memperoleh berbagai sponsor. Tentu saja, selain faktor raihan juara, setiap sponsor yang ingin menjadi mitra akan memperhitungkan popularitas dan jumlah fans dari klub sepak bola bersangkutan. Jumlah ini sangat penting karena menyangkut sebaran, populasi setiap fans di seluruh dunia dan hal lain yang terkait dengan pertimbangan bisnis. Semakin banyak jumlah fans dan semakin menyebar populasi ke seluruh penjuru dunia tentu semakin mahal tarifnya tetapi juga semangkin menguntungkan bagi perusahaan yang bersedia menjadi sponsor.

Hingga saat ini manajemen klub sepak bola Mancheseter United (MU) mengklaim memiliki jumlah fans paling banyak di dunia. Pada tahun 2011 MU mengumumkan sedikitnya memiliki 659 juta fans yang tersebar di seluruh dunia. Jumlah tersebut muncul dari riset pasar yang dilakukan oleh Kantar, sebuah lembaga survei yang ditunjuk oleh MU melakukan survei jumlah penggemarnya di seluruh dunia. Survei tersebut dilakukan di 39 negara dengan sampling 54.000 orang, dari Juni hingga Agustus 2011. Dari total 659 juta penggemar MU, Kantar mengatakan jika sebagian (325 juta) hidup di wilayah Asia Pasifik, 173 juta di Timur Tengah dan Afrika, 90 juta di Eropa dan 71 di kawasan Amerika. Ditinjau dari segi rata-rata penduduk yang menggemari MU, Indonesia menempati urutan ketiga (22,5 persen), di bawah Korea Selatan 30,6 persen dan Vietnam dengan 29,2 persen. (Sumber:http://www.bbc.com/news/ magazine-21478857)

Kendati dilakukan oleh lembaga survey terpercaya, namun hasilnya belum tentu akurat. Sebab berselang dua bulan hasil survei Kantar dirilis, Oktober 2011 perusahaan sport asal Jerman, Sport +Market juga merilis daftar klub sepak bola yang memiliki paling banyak penggemar di dunia. Sport + Market mengambil sampel 1000 orang dari 34 negara untuk melakukan survei 13 klub sepak bola. Namun yang dirilis hanya 10 besar klub sepak bola yang memiliki jumlah fans terbanyak di dunia. Hasil survei tersebut memang 
menempatkan MU sebagai klub sepak bola yang paling banyak memiliki fans di dunia dengan jumlah 354 bukan 659 seperti yang dirilis Kantar. Berikut ini daftar 10 klub sepak bola dengan fans terbanyak versi Sport +Market (Sumber :http://talksport.com/ magazine/big-picture):

1. Manchester United

Asal Negara: Inggris

Jumlah fans: Sekitar 354 juta.

2. Barcelona

Asal Negara: Spanyol

Jumlah Fans: Sekitar 270 Juta.

3. Real Madrid

Asal Negara: Spanyol

Jumlah Fans: Sekitar 174 juta.

4. Chelsea

Asal Negara: Inggris

Jumlah Fans: Sekitar 135 juta.

5. Arsenal

Asal Negara: Inggris

Jumlah Fans: Sekitar 113 juta.

6. AC Milan

Asal Negara: Italia

Jumlah Fans: Sekitar 99 juta.

7. Liverpool

Asal Negara: Inggris

Jumlah Fans: Sekitar 71 juta.

8. Inter Milan

Asal Negara: Italia

Jumlah Fans: Sekitar 49 juta.

9. Bayern Muenchen

Asal Negara: Jerman

Jumlah Fans: Sekitar 24 Juta.

10. Juventus

Asal Negara: Italia

Jumlah Fans: Sekitar 20 Juta.

Laporan survei Sport+Market tersebut menunjukkan ada relasi antara kemenangan yang diraih sebuah klub sepak bola pada beberapa liga terhadap jumlah fans. Manchester United (MU) merupakan klub pertama di Inggris yang hingga saat ini berhasil meraih treble winner. Pada satu musim MU berhasil menyabet juara Premier League, Piala FA dan liga Champions secara bersamaan sekaligus. Ini menjadi bernilai lebih karena liga Inggris termasukyang paling populer di dunia. Apalagi juara liga Champion diraih MU saat melawan Bayern Munchen melalui drama injury time. Sebagai raksasa klub sepak bola Eropa, saat itu MU memang sedang berada di puncak kejayaannya. MU memiliki sederet pemain bintang dunia yang tidak teputus sepanjang musim. Nama besar pemain bintang seperti Cristiano Ronaldo, David Beckham, Ryan Giggs, Dwight Yorke, Wayne Rooney yang turut mengangkat pamornya MU juga memiliki sejarah yang cukup panjang sebagai klub sepak bola, dan yang paling penting MU berhasil memiliki prestasi sebagai juara yang stabil. Di topang oleh manajemen, keuangan, promosi dan kekuatan industri media massa, telah menjadikan MU sebagai klub sepak bola yang memiliki fans paling banyak di dunia.

Fenomena fans club suatu klub sepak bola yang banyak digilai terutama oleh kaum muda perkotaan merupakan penampakan dari subkultur tersebut. Subkultur kaum muda tersebut berkomunikasi melalui tindakan konsumsi mereka terhadap budaya pop. Seperti dijelaskan Hedige (Storey, 2007: 151) subkultur kaum muda 'menaruh perhatian pertama dan terutama pada konsumsi'. Konsumsi budaya pop tersebut menciptakan identitas tersendiri. Terbentuk dan terpeliharanya budaya populer sangat dipengaruhi oleh kontak antarbudaya dan komunikasiantarbudaya. Artinyakomunikasi antarbudaya dan budaya populer memiliki hubungan yang sangat penting. Ada empat karakteristik signifikan budaya populer: (1) budaya populer diproduksi industri-industri budaya, (2) budaya populer berbeda dari budaya rakyat, (3) budaya populer ada di mana-mana, (4) budaya populer memiliki satu fungsi sosial (Martin dan Nakayama, 2004). 


\section{SIMPULAN}

Melalui berbagai penyelenggaraan kompetisi laga sepak bola, seperti liga Champions-memunculkan kegembiraan bersama di kalangan fans sepak bola. Kegembiraan tersebut memiliki kemampuan melahirkan keyakinan bersama akan suatu nilai. Keyakinan bersama yang muncul tersebut diproduksi melalui berbagai perayaan atau upacara bersama. Tanpa disadari sesunguhnya perayaan tersebut digerakkan oleh kehendak kapitalisme global yang menyusun strategi penyebaran ritualnya di atas motif pengumpulan keping-keping keuntungan (profit) material. Sehingga pada gilirannya, keyakinan bersama tersebut menciptakan kelas (kotak) sosial atau kultur baru yang dikenal sebagai subkultur. Fenomena fans club suatu klub sepak bola yang banyak digilai terutama oleh kaum muda perkotaan merupakan penampakan dari subkultur tersebut.

Para penggemar adalah bagian paling tampak dari khalayak teks dan praktik budaya pop. Penggemar selalu dicirikan (mengacu pada asal-usul istilahnya) sebagai suatu kefanatikan yang potensial. Hal ini berarti bahwa kelompok penggemar dilihat sebagai pelaku yang berlebihan dan berdekatan dengan kegilaan (Storey, 2007: 157). Fenomena kegilaan penggemar tersebut dapat terjadi karena mereka korban pasif dari patologis media massa. Fenomena tersebut sekaligus menandai adanya indikasi transisi dari masyarakat agrikultural menuju masyarakat industrial dan urban. Kegilaan fans tersebut sebenarnya memiliki pola yang dapat dibaca sebagai sebuah upacara atau ritual modernitas. 


\section{DAFTAR PUSTAKA}

Anderson, Benedict. 1999. Komunitaskomunitas Imajiner, Asal-usul dan Penyebaran Nasionalisme(Terj). Yogyakarta: Pustaka Pelajar.

Barker, Chris. 2005. Cultural Studies, Teori dan Praktek. (Terj).Yogyakarta:Bentang Pustaka.

Charon, John M. 2007. Symbolic Interactionism: An Introduction, An Interpretation, An Integration. New Jersey: Pearson Prentice Hall.

Coakley, Jay. 2001. Sport in Society: Issues and Controversies. London: McGraw-Hill.

Fiske, Jhon. 1987. Television Culture London: Routledge.

Hogg, Michael A, dan Terry J. Deborah (ed). 2001. Social Identity Processes in Organizational Contexts. Philadelphia: Psychology Press.

Jacobson, Beth. 2003. "The Social Psychology of the Creation of a Sports Fan Identity: A Theoretical Review of The Literature" Athletic Insight, Volume 5, Issue 2, Juni 2003.

Marcia, James E. 1993. Ego Identity, A Handbook for Psychosocial Research. New York: Springer Verlag.

Martin, Judith N. dan Thomas K. Nakayama. 2004. Intercultural Communication in Context. Boston: McGraw-Hill.
Munro, Clayton Edward Steven. 2006. Sports Fan Culture $\mathcal{E}$ Brand Community: An Ethnographic Case Study of The Vancouver Canucks Booster Club. Faculty of Graduate Studies (Human Kinetics). University of British Columbia.

Samovar, Larry A., Richard E. Porter, Edwin R. McDaniel. 2010. Communication Between Cultures. Boston: Cangage Learning

Storey, John, 2007. Cultural Studies dan Kajian Budaya Pop (Terj). Yogyakarta: Jalasutra.

Tomlinson, J. 1999. Globalization and Culture. Cambridge, UK: Polity Press.

Valdivia, Angharad $\mathrm{N}$ [ed]. 2006. A Comparison to Media Studies. USA: Blackwell Publishing.

\section{Website}

http://www.bbc.com/news/magazine21478857

http://talksport.com/magazine/bigpicture/2011-10-13/worlds-mostpopular-football-club-revealed-manunited-liverpool-arsenal-barca-real-orchelsea 
INFORMASI Kajian Ilmu Komunikasi Volume 46. Nomor 2. Desember 2016 